\title{
Effects of nano-silica treatment on the flexural post cracking behaviour of polypropylene macro-synthetic fibre reinforced concrete
}

\author{
Pietro Di Maida ${ }^{\mathrm{a}}$, Corrado Sciancalepore ${ }^{\mathrm{b}}$, Enrico Radi ${ }^{\mathrm{a}, *}$, Federica Bondioli $^{\mathrm{c}}$ \\ a Dipartimento di Scienze e Metodi Dell'Ingegneria, Università di Modena e Reggio Emilia, Italy \\ b INSTM, National Interuniversity Consortium of Materials Science and Technology, Florence, Italy \\ ' Dipartimento di Ingegneria Industriale, Università di Parma, Italy
}

\section{A R T I C L E I N F O}

Article history:

Received 15 November 2017

Received in revised form 15 January 2018

Accepted 16 January 2018

Available online $\mathrm{xxx}$

Keywords:

Macro synthetic fibre reinforced concrete (MSFRC)

Polypropylene

Nano silica

Sol gel

Interface transition zone

Post cracking behaviour

\section{A B S T R A C T}

The effects of a surface nano-silica treatment, carried out with the sol gel method, on the post-cracking behaviour of polypropylene macro-synthetic fibre reinforced concrete are experimentally investigated here for the first time. The present study extends previous experimental and analytical investigations on the corresponding improvement of the bonding properties of a single synthetic macro fibre, performed by means of pull-out test. Scanning electron microscopy is adopted here to explore the changes in the morphological characteristics of polypropylene macro synthetic fibres, before and after mixing in the concrete matrix. A comparative analysis, carried out with three-point bending tests on notched beam specimens, is used to evaluate the effects of the nano-silica treatment on the concrete post cracking behaviour. Increase in concrete toughness and residual post-cracking strength is recorded due to improved adhesion between fibres and the concrete matrix and to the consequent increase in the frictional shear stress generated during the fibre pull-out, especially for large crack opening. As shown by the SEM images, the nano-treatment favours the bonding of the concrete hydration products to the surface of the treated fibres, thus ensuring strengthening of the interface transition zone. In addition, the links between the nano-silica coating and the concrete hydration products improve the frictional shear stress and thus the overall energy absorption, as denoted by the increase of the residual strength during the post-cracking phase.

\section{Introduction}

Concrete is one of the most widespread materials used for buildings and constructions because of its many benefits in terms of high performance, economic purposes and versatility. As well known, plain concrete exhibits a high compressive strength. However, it suffers a limited tensile strength that makes it classifiable as brittle material. To overcome this limit, concrete is usually reinforced with materials that provide ductility and tensile strength after first cracking. The most common application is certainly reinforced concrete (RC) with steel bars or webs, which today is massively used in most civil engineering structures. Fibre reinforced concrete (FRC) with short fibres of various materials (steel, glass, polymeric, natural, carbon etc.) has developed over the last 50 years as an alternative solution to plain concrete or RC. If compared to plain concrete, FRC shows greater toughness, that is the capacity of energy absorption during the fracture process, and higher post cracking tensile strength. Assessment of FRC properties required an intensive study in terms of experimentation and modelling until it was introduced into the Model Code 2010 [1], which is currently the most authoritative and updated FRC design guideline. Steel fibres are the most commonly used for FRC,

\footnotetext{
* Corresponding author.

Email address: eradi@unimore.it (E. Radi)
}

even if they exhibit some problems due to corrosion in alkaline or chemically aggressive environments and to their electromagnetic properties [2]. For these reasons and for others of economic nature, there has been an increasing interest in synthetic fibres of various types of materials (polypropylene, polyethylene, polyvinyl chloride, polyethylene terephthalate, etc.) in recent years. In particular, polypropylene (PP) fibres display high stability in the chemical concrete environment without the critical features of steel fibres [3]. Two class of synthetic fibres are usually employed for FRC: micro-synthetic fibres (micron order diameters), which are used for contrasting micro cracking of cement composites resulting from plastic shrinkage [4], and macro-synthetic fibres ( $\mathrm{mm}$ order diameters), which have comparable dimensions with steel fibres and can equally improve concrete toughness and tensile strength [5]. For their properties, the macro-synthetic fibres have increased their commercial attractiveness over the years, being used in many civil engineering applications such as concrete pavements (used for industrial floors, roads, harbour piers), tunnels shotcrete (fibre reinforced sprayed concrete) and precast industry [6-11]. Despite the increased use of macro-synthetic fibres, they also display some peculiar weakness mainly related to the low elastic modulus, if it is compared to that of steel fibres [12], high deformability in time (creep) $[13,14]$ and poor adhesion to the cement matrix due to the chemical inertia of PP and polymeric materials in general [15]. In order to mitigate the low adhesion of PP fibres to the cement matrix, several mechanical measures have been implemented 
such as giving a favourable shape to the fibres (crimped, undulated, fibrillated, embossed, etc.) that increase the grip [16,17]. Two other methods have been used to improve the fibre surface characteristics: the first one, of physical nature, aims to increase the surface micro roughness [18] and the second one, of chemical nature, tends to increase the functionality of the surface by improving the bonding with the hydration products of the cement matrix [19]. The proper working mechanism of FRC requires the progressive pull-out of fibres from the matrix without breaking during the post cracking process. During this process, each fibre experiences progression of debonding, then followed by frictional slippage between fibre and matrix. In this way, energy dissipation is promoted so that FRC becomes able to display ductile behaviour [20]. The pullout of the macro synthetic fibres is mainly related to the properties of the Interface Transition Zone (ITZ), that is the crossing zone between the fibre and the matrix. Due to its chemical-physical characteristics, the ITZ is identified as the weak zone where the local rupture of the fibre-matrix link occurs [21]. As reported in some experimental works [22], the mechanical properties of fibrous reinforced cementitious composites can be improved by increasing the local strength and micro hardness of the ITZ. This purpose can be achieved by reducing the porosity of the ITZ, by adding nano-fillers or polymers to the concrete mixture $[23,24]$ or by performing chemical treatments on the outer surface of the fibre [25] that increase the functionality and the specific contact surface area, in order to produce an anchoring effect. The influence of various treatments on the fibres adhesion were mainly studied and validated by pull-out tests on single-fibre. However, the strengthening effects observed in the pull-out response of a single treated fibre may only partially extend to the macroscopic flexural behaviour of macro synthetic fibre reinforced concrete (MSFRC) [26] depending on fibre dosage and other random factors, such as the fibres distribution and orientation [27-29], which may reduce the overall effects of the advantages observed in the pull-out of a single treated fibre.

The present investigation provides the first experimental data available in literature on the post-cracking flexural behaviour of MSFRC whose fibres are treated with nano-silica, thus extending previous experimental and theoretical studies on the efficiency of nano-silica treatment on single fibre pull-out [30,31]. The effectiveness of the treatment has been evaluated in terms of toughness and post cracking residual strength of MSFRC beam specimen. In order to improve the interactions between the synthetic fibres and cementitious matrix, the superficial functionalization of PP fibres was achieved by a base-catalysed sol-gel treatment. Sol-gel reactions promote the growth of colloidal particles and their subsequent network formation through the hydrolysis and condensation reactions of inorganic alkoxide monomers. Tetraethoxysilane (TEOS) was used here as metal alkoxide. Under base-catalysed conditions, TEOS allows to obtain highly branched clusters due to the longer time that monomers need to aggregate in a most thermodynamically stable arrangement $[32,33]$. Adhesion of the so obtained silica nanoparticles on the PP fibre surface was evaluated by scanning electron microscopy and the resulting enhancement in the interfacial strength between treated fibres and cementitious matrix was characterized by mechanical three point bending tests.

\section{Materials and methods}

\subsection{Reference concrete}

Mix proportions for the reference concrete are reported in Table 1. The used cement was Portland Cement type CEM II/B-LL 32.5R ac-
Table 1

Reference concrete mix proportions.

\begin{tabular}{ll}
\hline Portland cement & $350 \mathrm{~kg} / \mathrm{m}^{3}$ \\
Water & $1501 / \mathrm{m}^{3}$ \\
Fine aggregate $(0-2 \mathrm{~mm})$ & $742 \mathrm{~kg} / \mathrm{m}^{3}$ \\
Coarse aggregate $(2-16 \mathrm{~mm})$ & $1058 \mathrm{~kg} / \mathrm{m}^{3}$ \\
Water/cement ratio & 0.43 \\
\hline
\end{tabular}

cording EN 197-1 with mechanical characteristics as reported in Table 2 . The used water/cement ratio was 0.43 . Crushed gravel with maximum size of $16 \mathrm{~mm}$ and controlled granulometric distribution, reported in Table 3, was used for coarse aggregate and river sand was used as fine aggregate. In order to classify the strength class of the reference concrete, compression tests were performed on three cubic specimen $150 \times 150 \times 150 \mathrm{~mm}^{3}$ according to UNI EN 12390-1:2002. The concrete was poured in cubic moulds and compacted properly so as not to have any voids. After $24 \mathrm{~h}$, the moulds were removed and test specimens were ripened to season. After 28 days of curing the specimens were tested in a compressive Metrocom testing machine ( $3000 \mathrm{kN}$ of capacity) to get the concrete cubic strength $R_{c}$ reported in Table 4.

Table 2

Cement characteristics.

\begin{tabular}{ll}
\hline Time & Cement compressive strength \\
\hline 2 days & $10 \mathrm{MPa}\left(>100 \mathrm{~kg} / \mathrm{cm}^{2}\right)$ \\
28 days & $32.5 \mathrm{MPa}\left(>325 \mathrm{~kg} / \mathrm{cm}^{2}\right)$ \\
\hline
\end{tabular}

Table 3

Characteristics of the aggregates.

\begin{tabular}{ll}
\hline Sieve size $(\mathrm{mm})$ ISO 3310-1/2 & Passing $(\%)$ \\
\hline 31.5 & 100.0 \\
22.4 & 100.0 \\
20 & 100.0 \\
16 & 99.8 \\
14 & 96.6 \\
12.5 & 93.5 \\
11.2 & 90.1 \\
10 & 87.2 \\
8 & 82.0 \\
6.3 & 76.9 \\
5.6 & 74.7 \\
4 & 63.4 \\
2 & 41.2 \\
1 & 26.1 \\
0.5 & 17.2 \\
0.25 & 9.6 \\
0.125 & 2.8 \\
0.063 & 0.6 \\
Bottom & 0.0 \\
Water abs. & $1.2-1.9$ \\
31.5 & 100.0 \\
\hline &
\end{tabular}

Table 4

Results of compressive tests.

\begin{tabular}{llll}
\hline Specimen & Compressive strength $(\mathrm{MPa})$ & $R_{\mathrm{cm}}(\mathrm{MPa})$ & $\mathrm{SD}(\mathrm{MPa})$ \\
\hline$R_{\mathrm{c} 1}$ & 30.67 & 30.50 & 0.20 \\
$R_{\mathrm{c} 2}$ & 30.25 & & \\
$R_{\mathrm{c} 3}$ & 30.56 & & \\
\hline
\end{tabular}




\subsection{Fibres}

The macro synthetic fibres (Fig. 1) consist of PP crimped monofilaments with a diameter of $0.78 \mathrm{~mm}$ and length of $49 \mathrm{~mm}$ (aspect ratio 63). The main properties of the used PP macro-synthetic fibres are reported in Table 5.

\subsection{Treatment methods}

The surface functionalization of PP fibres with silica nanosphere was carried out by sol-gel process, as reported by Di Maida et al. [30]. In particular, the fibres were fixed on a solid support to form a brush structure and immersed in the reaction solution throughout the treatment period. This device avoided collisions between the fibres and floating phenomena, optimizing the nanoparticle adhesion to the fibre surface.

The materials used for the sol-gel treatment were ethanol (EtOH), ammonium hydroxide solution $(\mathrm{NH} 4 \mathrm{OH}, 28 \mathrm{wt} \%)$ and tetraethyl-orthosilicate (TEOS). All materials are high purity reactants (Sigma-Aldrich) and were used without any purification.

\section{SEM and EDX characterization}

The morphology and distribution of silica nanoparticles on PP macro-synthetic fibres surface were evaluated by scanning electron microscopy (SEM), using the field emission SEM Nova NanoSEM 450 (FEI Company, USA). Acquired images were obtained in immersion lens mode using the "through-the-lens" detector (TLD), with accelerating voltage (HV) of $10 \mathrm{kV}$, spot size of 3 and working distance (WD) of $5 \mathrm{~mm}$. The elemental composition of the nanoparticles was verified by the energy-dispersive X-ray spectroscopy system (X-EDS) QUANTAX-200 (Bruker, Germany).

In order to evaluate the fibre-concrete interface after the concrete curing, cement-based cylindrical samples, with base diameter and width of $30 \mathrm{~mm}$, containing both treated and untreated fibres were prepared. Cement mortar with a mix proportion by weight of cement, water and sand respectively equal to 1:1.5:0.5 was used to prepare the test specimens.

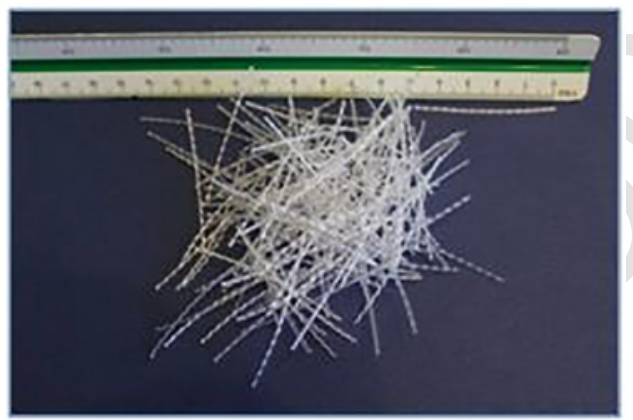

Fig. 1. Macro synthetic PP fibres.

Table 5

Macro synthetic fibres properties and characteristics.

\begin{tabular}{ll}
\hline Diameter $(\mathrm{mm})$ & 0.78 \\
Lenght $(\mathrm{mm})$ & 49 \\
Aspect ratio & 63 \\
Material & Polypropylene \\
Tensile Strenght $(\mathrm{MPa})$ & 500 \\
\hline
\end{tabular}

The samples were gradually broken in order to limit the perturbation on the fibre surface. The surface conformation of the fibres was examined by the environment scanning electron microscopy ESEM QUANTA 200 (FEI Company, USA). Backscattered electrons were used to collect the images in low vacuum mode with accelerating voltage (HV) of $15 \mathrm{kV}$, spot size of 6 and working distance (WD) of $14 \mathrm{~mm}$.

\section{Bending test and experimental program}

Three point bending test, according the EN 14651 [34] standard, were executed on prismatic specimens with dimension of $150 \times 150 \times 600 \mathrm{~mm}^{3}$. According to the requirements of EN 14651 standard, six MSFRC beams were casted using the reference concrete described in Section 2.1, three beams with $5 \mathrm{~kg} / \mathrm{m}^{3}$ (about $0.5 \%$ volume per cent) of treated fibres and three beams with the same dosage of untreated fibres. The specimens were casted in plastic moulds and covered with plastic sheets for 2 days. Then, they were demoulded and stored to curing for 28 days. After the curing period the specimens were notched (notch $25 \mathrm{~mm}$ in length and $5 \mathrm{~mm}$ in width) at the mid-span, presenting a total height $h_{\mathrm{sp}}=h-25=125 \mathrm{~mm}$ between the tip of the notch and the top surface in the mid-span section.

The samples casted with untreated macro-synthetic fibres were named with code NT and the samples with treated macro-synthetic fibres with the code $\mathrm{T}$ followed by the sample number.

The setting of the test according the EN1 4651 standard is described in Fig. 2 where the specimens are placed on two roller supports, with a free span of $500 \mathrm{~mm}$ and are subjected to three point bending test.

After the single specimen was correctly located under the three point testing machine, a displacement transducer was mounted across the mouth of the notch as sketched in Fig. 2 in order to measure the CMOD (Crack Mouth Opening Displacement), namely the crack opening variation with the load increasing. The tests were conducted with an Instron UTM 5582 machine, by increasing the CMOD at the constant rate of $0.05 \mathrm{~mm} / \mathrm{min}$ initially. When CMOD reached $0.1 \mathrm{~mm}$ then the rate of increase of CMOD changed to $0.2 \mathrm{~mm} / \mathrm{min}$. During the first $2 \mathrm{~min}$ of the test, the values of the load and the corresponding CMOD were recorded at a rate of $5 \mathrm{~Hz}$, then reduced to

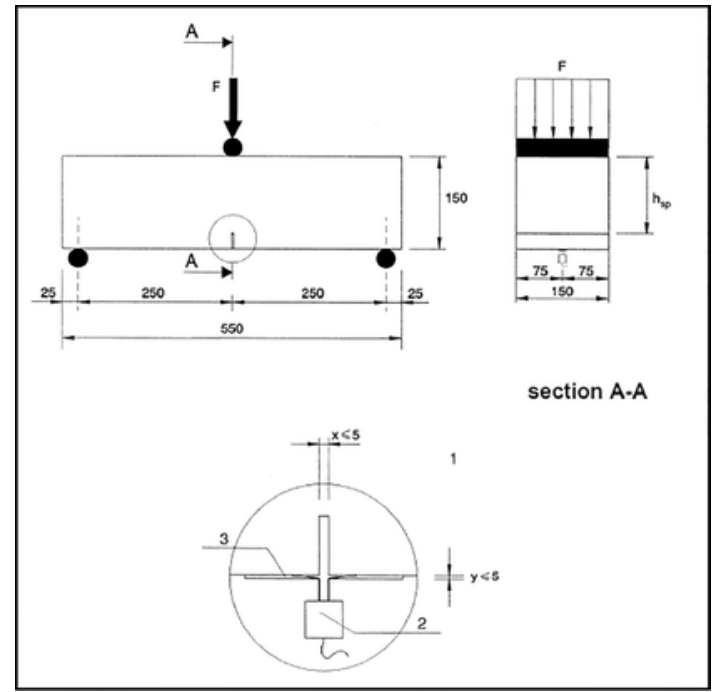

Fig. 2. Setting of the three point banding test (EN 14651). 
$1 \mathrm{~Hz}$. The tests were terminated at the CMOD value of $4 \mathrm{~mm}$. A typical experimental curve is shown in Fig. 3. The load values of interest can be determined from this diagram. In particular, from the experimental results one can obtain the maximum applied load in the CMOD interval ranging between 0 and $0.05 \mathrm{~mm}$, namely $F_{\mathrm{L}}$, and the loads corresponding respectively to CMOD values of $0.5 \mathrm{~mm}, 1.5 \mathrm{~mm}, 2.5 \mathrm{~mm}$ and $3.5 \mathrm{~mm}$, defined by $F_{1}, F_{2}, F_{3}$ and $F_{4}$, respectively.

The cracking and post cracking flexural tensile strengths can be extracted from these load values. In particular, the limit of proportionality (LOP) corresponds to the maximum applied load $F_{\mathrm{L}}$ and the residual post cracking strengths $f_{R j}$ correspond to the loads $F_{1}, F_{2}, F_{3}, F_{4}$ according to the following expressions [34]:

$$
\mathrm{LOP}=f_{c t, \mathrm{~L}}^{f}=\frac{3 F_{\mathrm{L}} l}{2 b h_{s p}^{2}}, \quad f_{R j}=\frac{3 F_{j} l}{2 b h_{s p}^{2}}(j=1,2,3,4)
$$

\section{Result and discussion}

\subsection{SEM images}

The SEM images of both sol-gel treated and untreated PP fibres are reported in Fig. 4 before mixing to the concrete matrix. Structures with nanometric dimension and spherical geometry can be observed on the surface of treated fibres (Fig. 4a, c, e).

These nanostructures are homogeneously distributed as a single layer on the surface of the fibre. Some nanoparticle aggregates can be distinguished preferably in correspondence to the fibre superficial irregularities, which are more clearly seen in the images of untreated fibres (Fig. 4b, d and f).

Similar characteristics of the single crimped macro synthetic fibre were already observed on the treated wires, used in the pullout tests [30]. On the other hand, the surface morphology of the untreated fibres shows completely different characteristics with respect to those previously described. In fact, the surface of untreated fibres appears smooth and regular, with some irregularities and discontinuities due probably to the extrusion and crimping processes.

The observed nanoparticles have a size distribution centred at $50 \mathrm{~nm}$ and a chemical composition based on silicon and oxygen, as confirmed by EDX elemental analysis (Fig. 5).

Therefore, silica nanoparticles produced by the sol-gel process exhibit good adhesion to the fibre surface and can act effectively in increasing interactions between the synthetic fibres and the concrete matrix.

The ESEM images of the fibre-concrete interface both for treated and untreated fibres are shown in Fig. 6. Untreated fibres have a smooth and polished surface, where very few hydration products are noticeable only in some localized areas (Fig. 6c, d). On the contrary,

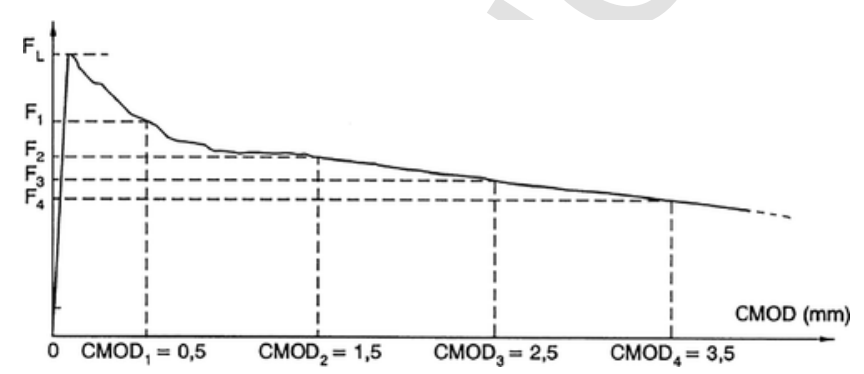

Fig. 3. Typical load - CMOD curve (EN 14651).
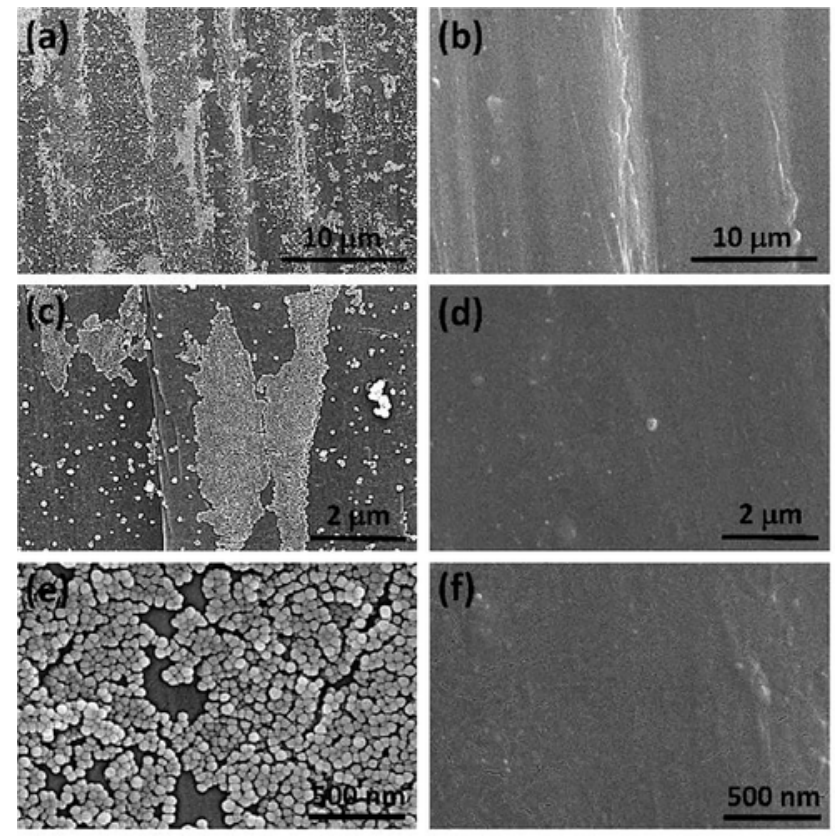

Fig. 4. SEM images of treated (a, c, e) and untreated PP fibres (b, d, f) at different magnification.

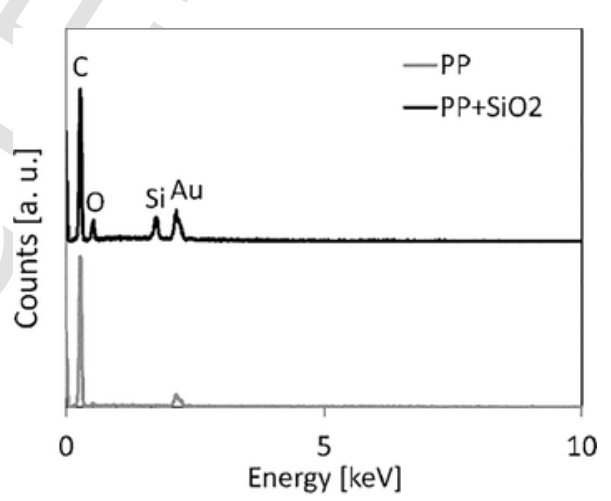

Fig. 5. EDX spectra of respectively treated and untreated fibres.

an almost uniform diffusion of the hydration products still attached to the surface of the fibres can be clearly distinguished in the treated fibres (Fig. 6a, b), thus indicating a strong interaction between the concrete matrix and the fibres.

\subsection{Load-CMOD diagrams}

The resulting diagrams of the three-point bending tests are shown in Figs. 7 and 8, where average diagrams are reported. All the graphs display the typical trend of the fibre reinforced concrete with macro synthetic fibres in which an initial elastic response is distinguished until the matrix first cracking strength is achieved, followed by a descending softening response representing the post cracking behaviour [35].

After the peak point, corresponding to the first cracking strength, an immediate decay in the load carrying capacity can be observed due to the low elastic modulus of the macro synthetic fibres with respect to the matrix one, until a minimum is reached at a CMOD about $0.5 \mathrm{~mm}$. After the minimum point, a rise in the applied load is observed, due to the activation of the debonding and pull-out mech- 

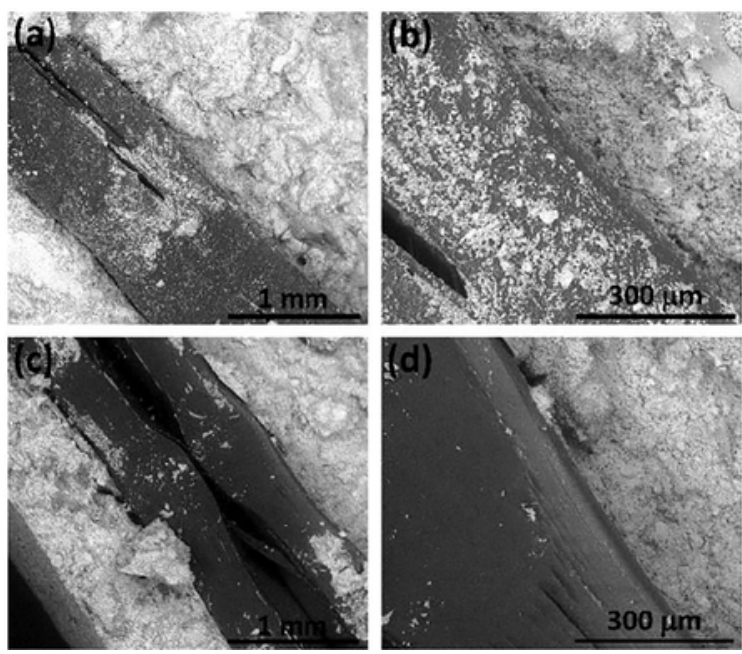

Fig. 6. ESEM images of respectively treated ( $a$ and $b$ ) and untreated (c and d) fibres after concrete curing.

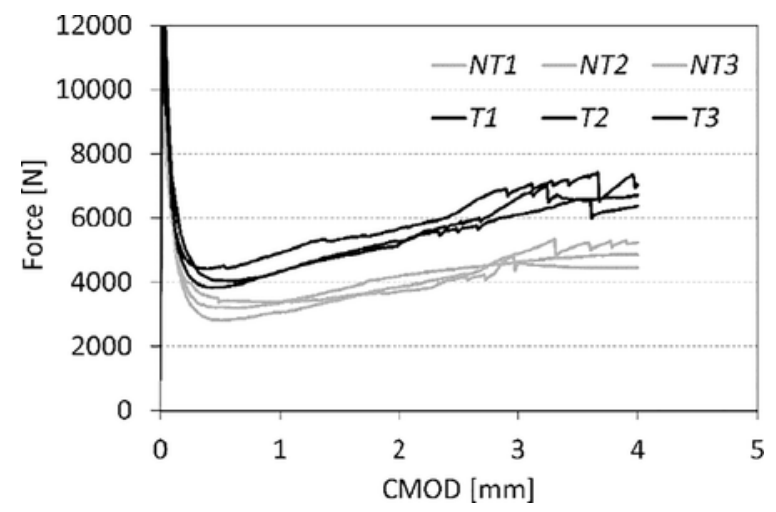

Fig. 7. Load-CMOD diagrams.

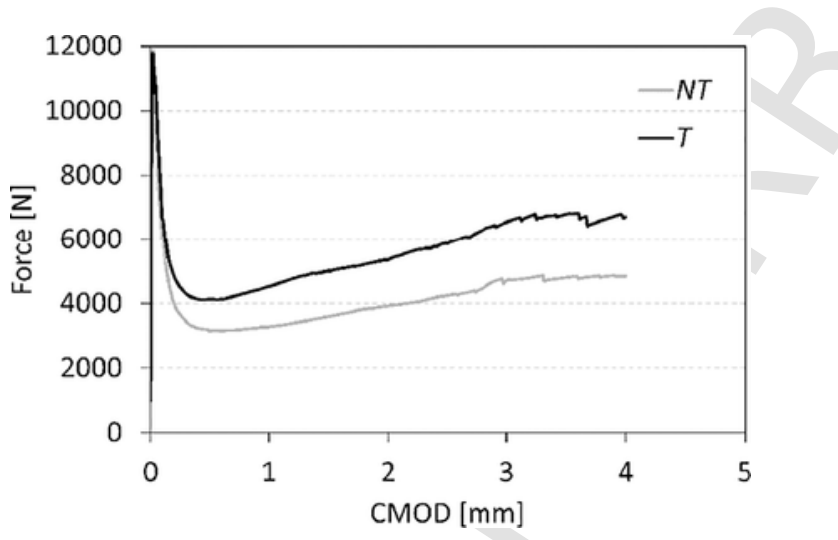

Fig. 8. Average load-CMOD diagrams.

anisms of the fibres put in evidence in [30] and modelled in [31]. In this part, small oscillations may occur due to the rupture of some fibres during the crack opening process.

The resulting load-CMOD curves, both in the case of treated and untreated fibres, have a good degree of homogeneity with low scattering, being comparable the number of fibres counted in the cracked section of each specimen. Using the expressions (1) it is possible to derive the LOP and residual post cracking strengths $f_{R j}$ from the rel- ative load values. Their values are given in Table 6, whereas the average values of the LOP and $f_{R j}$ residual strengths are reported in Table 7. From the values reported in Tables 6 and 7, it can be noted that the sol-gel treatment has a positive effects on the FRC flexural strength. As well known from the studies on FRC [36], the addition of fibres, both in the case of treated and untreated fibres, does not produce substantial effects on the FRC first cracking strength, which remains almost unchanged.

On the contrary, appreciable effects on post-cracking residual strengths are obtained for treated fibres. In particular, an increase of about $30 \%$ is observed for $f_{R 1}$, whereas the following residual post cracking strengths $f_{R 2}, f_{R 3}, f_{R 4}$ increases of about $40 \%$. The lower effect on residual post cracking strength $f_{R 1}(\mathrm{CMOD}=0.5 \mathrm{~mm})$ can be attributed to the low elastic modulus of the macro synthetic fibres that, for low CMOD values, is the predominant factor in MSFRC performance and determine the typical dropping in the curvature of the load-CMOD diagram. For increasing values of CMOD instead, when the main factor becomes the energy absorption resulting from the pull-out, the effects of nano-silica treatment become more evident. This result is due to the positive influence that the nano treatment has on the pull-out behaviour of the fibres, both in the debonding phase and in the subsequent frictional phase. As observed for the pull-out of a single treated PP fibre [30,31], the frictional shear stress between fibre and matrix displays a steeper hardening behaviour with fibre slippage, thus increasing the amount of energy required for the complete extraction of the fibres. A similar trend is reproduced also in the macroscopic post-cracking behaviour of MSFRC, even if the post cracking load does not reach the first cracking load value and thus the global behaviour remains of softening type.

Note also that the increase in energy absorption observed in Figs. 7 and 8 is due only to the enhanced pullout behaviour of the synthetic fibres crossing the cracked section, not to the formation of multiple or diffuse cracking in the concrete, since a single macrocrack propagates within the specimen.

Table 6

Loads $F_{j}$ and post cracking residual strengths $f_{R j}$.

\begin{tabular}{lllllll}
\hline Sample & NT1 & NT2 & NT3 & T1 & T2 & T3 \\
\hline$F_{\mathrm{L}}(N)$ & 12,392 & 12,445 & 12,221 & 11,040 & 11,733 & 12,743 \\
$F_{1}(N)$ & 3410 & 3216 & 2822 & 3847 & 4494 & 4059 \\
$F_{2}(N)$ & 3774 & 3534 & 3457 & 4869 & 5341 & 4802 \\
$F_{3}(N)$ & 4420 & 4116 & 4217 & 5841 & 6203 & 5595 \\
$F_{4}(N)$ & 4794 & 4464 & 5160 & 6580 & 7220 & 6597 \\
$\mathrm{LOP}(\mathrm{MPa})$ & 3.97 & 3.98 & 3.91 & 3.53 & 3.75 & 4.08 \\
$f_{\mathrm{R} 1}(\mathrm{MPa})$ & 1.09 & 1.03 & 0.90 & 1.23 & 1.44 & 1.30 \\
$f_{\mathrm{R} 2}(\mathrm{MPa})$ & 1.21 & 1.13 & 1.11 & 1.56 & 1.71 & 1.54 \\
$f_{\mathrm{R} 3}(\mathrm{MPa})$ & 1.41 & 1.32 & 1.35 & 1.87 & 1.98 & 1.79 \\
$f_{\mathrm{R} 4}(\mathrm{MPa})$ & 1.53 & 1.43 & 1.65 & 2.11 & 2.31 & 2.11 \\
\hline
\end{tabular}

Table 7

Average post cracking residual strengths $f_{R j}$.

\begin{tabular}{lll}
\hline Samples & NT1-NT2-NT3 & T1-T2-T3 \\
\hline LOP $(\mathrm{MPa})$ & 3.95 & 3.79 \\
$\mathrm{SD}(\mathrm{MPa})$ & 0.04 & 0.27 \\
$f_{\mathrm{R} 1}(\mathrm{MPa})$ & 1.01 & 1.32 \\
$\mathrm{SD}(\mathrm{MPa})$ & 0.10 & 0.11 \\
$f_{\mathrm{R} 2}(\mathrm{MPa})$ & 1.15 & 1.60 \\
$\mathrm{SD}(\mathrm{MPa})$ & 0.05 & 0.09 \\
$f_{\mathrm{R} 3}(\mathrm{MPa})$ & 1.36 & 1.88 \\
$\mathrm{SD}(\mathrm{MPa})$ & 0.05 & 0.10 \\
$f_{\mathrm{R} 4}(\mathrm{MPa})$ & 1.54 & 2.18 \\
$\mathrm{SD}(\mathrm{MPa})$ & 0.11 & 0.12 \\
\hline
\end{tabular}




\section{Conclusions}

Nanosilica-based treatment by means of the sol-gel process was successfully conducted on macro-synthetic PP fibres in order to improve the interaction area at the interface between the synthetic fibres and the concrete matrix. After sol-gel treatment, SEM images denote the presence of a homogeneous and diffused silica nanoparticle coating on the fibre surface. Moreover, ESEM images show a remarkable increase of hydration products on the surface of treated fibres compared to untreated ones, after mixing them with the cement matrix. Three point bending tests on notched beams were performed to investigate on the effect of the nano-silica treatment over the post cracking behaviour of MSFRC. The main experimental results show that the concrete flexural strength is not affected by the use of the nano-silica coating while the post cracking residual strengths relative to the treated fibres show variable increments. In particular, the post cracking strength increases for large crack opening, namely it increases about $40 \%$ for $C M O D \geq 1.5 \mathrm{~mm}$. The greater values of the post cracking strength lead to a global rise of the load-CMOD diagrams denoting a stronger capacity of the treated fibres to absorb and dissipate energy, during the debonding and pullout phases. The enhancement of the post cracking behaviour of the MSFRC by the use of the nano-silica treatment can be explained by a local modification of the ITZ depending on the products bonded to the surface of the treated fibres, which can be observed from the images here reported. These products are the result of the high reactivity of the nano-silica layers and they generate a strengthening mechanism depending on two main factors. The first one is that the presence of the nano-silica layers, which are very chemically compatible with the cement matrix, produces additional hydration products with the result of a water reduction in the ITZ, thus decreasing its weakness. The second one is the increase of the specific surface produced by the adhesion of the hydration products that creates a micro mechanical anchoring, thus improving the frictional shear stress required for the fibre pullout. The enhancement of the adhesion properties due to the modification of the ITZ increases the hardening behaviour during the debonding and frictional pull-out phases of a single treated fibre, as observed in [30] and modelled in [31]. A similar improvement has been found here also for the post cracking flexural behaviour of MSFRC beam specimen, thus proving the effectiveness of the nano-treatment proposed in [30] at the macroscale. In particular, the increase observed both in the synthetic fibre bonding properties and in MSFRC toughness is larger than that induced by chemical treatments aiming to enhance the chemical affinity between the fibre and the cement matrix. The latter treatments provide indeed a maximum increases in the residual strengths limited to $17.6 \%$ [19]. The enhancement observed in MSFRC toughness is instead comparable to that obtained by performing physical treatments on synthetic fibres, aiming to generate a micro roughening to the surface in order to provide mechanical anchoring, such as by Argon and Oxygen plasma, which showed a toughness increase of $27 \%$ [37]. A possible limitation in the experimental evaluation of the FRC toughness and post cracking strength is the high scattering of the results of the bending test caused not only by the heterogeneity of the concrete matrix but also by the small specimen geometries and by random factors determining the number of fibres crossing the cracked section [38]. The former data on the enhanced flexural behaviour of a treated MSFRC here provided will contribute in future works for the assessment of accurate modelling of the mechanical response of more complex structures like frames and plates $[7,8]$ made of treated MSFRC.
Regarding the sustainability of the industrial process, even if the silica precursor is quite expensive, the suggested treatment can be considered as applicable on industrial level taking into account for the small quantities that are used. Moreover, the treatment can be optimized to be added in line after the fibre extrusion process.

\section{Acknowledgements}

This work was supported by the Italian Ministry of Education, University and Research (MIUR) within the framework of the Project PRIN "COAN 5.50.16.01" code 2015JW9NJT.

\section{Supplementary materials}

Supplementary material associated with this article can be found, in the online version, at doi:10.1016/j.mechrescom.2018.01.004.

\section{References}

[1] Fédération Internationale du Béton (FIB): Model Code 2010 - final draft, Vol. 1, Bulletin 65, and Vol. 2, Bulletin 66, Lausanne, Switzerland, 2012.

[2] K. Kosa, A.E. Naaman, Corrosion of steel fibre reinforced concrete, Mater. J. 87 (1990) 27-37.

[3] Z. Zheng, D. Feldman, Synthetic fibre-reinforced concrete, Prog. Polym. Sci 20 (2) (1995) 185-210.

[4] T. Aly, J.G. Sanjayan, F. Collins, Effect of polypropylene fibres on shrinkage and cracking of concretes, Mater. Struct. 41 (10) (2008) 1741-1753.

[5] S. Yin, R. Tuladhar, F. Shi, M. Combe, T. Collister, N. Sivakugan, Use of macro plastic fibres in concrete: a review, Constr. Build. Mater. 93 (2015) 180-188.

[6] A. Nobili, L. Lanzoni, A.M. Tarantino, Experimental investigation and monitoring of a polypropylene-based fibre reinforced concrete road pavement, Constr. Build. Mater. 47 (2013) 888-895.

[7] E. Radi, P. Di Maida, Analytical solution for ductile and FRC plates on elastic ground loaded on a small circular area, J. Mech. Mater. Struct. 9 (2014) 313-331.

[8] L. Lanzoni, A. Nobili, E. Radi, A. Sorzia, Failure mechanism of FRC slabs on non-local ground, Meccanica 51 (10) (2016) 2473-2492.

[9] A.M. Alani, D. Beckett, Mechanical properties of a large scale synthetic fibre reinforced concrete ground slab, Constr. Build. Mater. 41 (2013) 335-344.

[10] E.S. Bernard, Design of fibre reinforced shotcrete linings with macro-synthetic fibres, In: Proceedings of Shotcrete for Underground Support XI, 2009. http://dc engconfintl.org/shotcrete/14.

[11] A. de la Fuente, R.C. Escariz, A.D. de Figueiredo, A. Aguado, Design of macro-synthetic fibre reinforced concrete pipes, Constr. Build. Mater. 43 (2013) 523-532.

[12] N. Buratti, C. Mazzotti, M. Savoia, Post-cracking behavior of steel and macro-synthetic fibre-reinforced concretes, Constr. Build. Mater. 25 (5) (2011) 2713-2722.

[13] A.J. Babafemi, W.P. Boshoff, Tensile creep of macro-synthetic fibre reinforced concrete (MSFRC) under uni-axial tensile loading, Cem. Concr. Compos. 55 (2015) 62-69.

[14] R. Vrijdaghs, M. di Prisco, L. Vandewalle, Creep deformations of structural polymeric macrofibres, in: P. Serna, A. Llano-Torre, S.H.P. Cavalaro (Eds.), Creep Behavior in Cracked Sections of Fibre Reinforced Concrete, Springer, Dordrecht, 2017, pp. 53-61.

[15] S. Wu, Polymer Interface and Adhesion, Marcel Dekker, New York, 1982.

[16] J.-P. Won, D.-H. Lim, C.-G. Park, Bond behavior and flexural performance of structural synthetic fibre-reinforced concrete, Mag. Concr. Res. 58 (6) (2006) $401-410$.

[17] A. Bentur, A. Peled, D. Yankelevsky, Enhanced bonding of low modulus polymer fibres-cement matrix by means of crimped geometry, Cem. Concr. Res. 27 (7) (1997) 1099-1111.

[18] V.C. Li, H.C. Wu, Y.W. Chan, Effect of plasma treatment of polyethylene fibres on interface and cementitious composite properties, J. Am. Ceram. Soc. 79 (3) (1996) 700-704

[19] P. Payrow, M.R. Nokken, D. Banu, D. Feldman, Effect of surface treatment on the post-peak residual strength and toughness of polypropylene/polyethylene-blended fibre-reinforced concrete, J. Compos. Mater. 45 (20) (2011) 2047-2054.

[20] M. Maalej, V.C. Li, T. Hashida, Effect of fibre rupture on tensile properties of short fibre composites, J. Eng. Mech. 121 (8) (1995) 903-913. 
[21] A. Bentur, S.T. Wu, N. Banthia, R. Baggott, W. Hansen, A. Katz, C.K.Y. Leung, V.C. Li, B. Mobasher, A.E. Naaman, R. Robertson, P. Soroushian, H. Stang, L.R. Taerwe, Fibre-matrix interfaces, in: A.E. Naaman, H.W Reinhardt (Eds.), High Performance Fibre Reinforced Cement Composites 2, E\&FN Spon, London, 1996, pp. 149-191.

[22] V.C. Li, H. Stang, Interface property characterization and strengthening mechanisms in fibre reinforced cement based composites, Adv. Cem. Based Mater. 6 (1) (1997) $1-20$

[23] C.-G. Park, J.-W. Lee, Effect of nanosilica and silica fume content on the bond properties of macro-synthetic fibre in cement-based composites, Mag. Concr. Res. 65 (3) (2013) 148-157.

[24] J.-W. Han, J-H. Jeon, C.-G. Park, Bond characteristics of macro polypropylene fibre in cementitious composites containing nanosilica and styrene butadiene latex polymer, Int. J. Polym. Sci. 2015 (2015), 207456.

[25] A.M. López-Buendía, M.D. Romero-Sánchez, V. Climent, C. Guillem, Surface treated polypropylene (PP) fibres for reinforced concrete, Cem. Concr. Res. 54 (2013) 29-35.

[26] C.S. Zhang, V.S. Gopalaratnam, H.K. Yasuda, Plasma treatment of polymeric fibres for improved performance in cement matrices, J. Appl. Polym. Sci. 76 (14) (2000) 1985-1996.

[27] I. Sevostianov, V. Levin, E. Radi, Effective properties of linear viscoelastic microcracked materials: Application of Maxwell homogenization scheme, Mech. Mater. 84 (2015) 28-43.

[28] I. Sevostianov, V. Levin, E. Radi, Effective viscoelastic properties of short-fibre reinforced composites, Int. J. Eng. Sci. 100 (2016) 61-73.

[29] T. Mishurova, N. Rachmatulin, P. Fontana, T. Oesch, G. Bruno, E. Radi, I. Sevostianov, Evaluation of the probability density of inhomogeneous fibre orien- tations by computed tomography and its application to the calculation of the effective properties of a fibre-reinforce composite, Int. J. Eng. Sci. 122 (2018) $14-29$.

[30] P. Di Maida, E. Radi, C. Sciancalepore, F. Bondioli, Pullout behavior of polypropylene macro-synthetic fibres treated with nano-silica, Constr. Build. Mater. 82 (39-44) (2015) 39-44.

[31] E. Radi, L. Lanzoni, A. Sorzia, Analytical modelling of the pullout behavior of synthetic fibres treated with nano-silica, Procedia Eng. 109 (2015) 525-532.

[32] C.J. Brinker, G.W. Sherrer, Sol-Gel Science: The Physics and Chemistry of Sol-Gel Processing, Accademic Press, Cambridge, 1990.

[33] L.L. Hench, J.K. West, The sol-gel process, Chem. Rev. 90 (1990) 33-72.

[34] EN 14651:2005, Test method for metallic fibred concrete - measuring the flexural tensile strength (limit of proportionality (LOP), residual), CEN European Committee for Standardization, Brussels, 2005.

[35] B.H. Oh, D.G. Park, J.C. Kim, Y.C. Choi, Experimental and theoretical investigation on the postcracking inelastic behavior of synthetic fibre reinforced concrete beams, Cem. Concr. Res. 35 (2) (2005) 384-392.

[36] M. di Prisco, G. Plizzari, L. Vandewalle, Fibre reinforced concrete: new design perspectives, Mater. Struct. 42 (9) (2009) 1261-1281

[37] H.R. Pakravan, F. Memariyan, Modification of low-surface energy fibers used as reinforcement in cementitious composites: a review, Polym.-Plast. Technol. Eng. 56 (3) (2017) 227-239.

[38] B. Parmentier, L. Vandewalle, F. Rickstal, Evaluation of the scatter of the post peak behavior of fibre reinforced concrete in bending: a step towards reliability, in: R. Gettu (Ed.), Proceedings of the 7th RILEM International Symposium on Fibre Reinforced Concrete: Design and Applications - BEFIB 2008, Chennai, 2008, pp. 133-143. 